\title{
Characterization of brown-black pigment isolated from soil bacteria, Beijerinckia fluminensis
}

\author{
Mahesh H. Joshi ${ }^{1}$, Ashwini A. Patil ${ }^{2}$, and Ravindra V. Adivarekar ${ }^{1}$ \\ ${ }^{1}$ Department of Fibers \& Textile Processing Technology, Institute of Chemical Technology \\ (ICT), Mumbai, Maharashtra, India. \\ ${ }^{2}$ Department of Chemical Engineering, Institute of Chemical Technology (ICT), Mumbai, \\ Maharashtra, India.
}

\section{ORCID}

Mahesh H. Joshi https://orcid.org/0000-0001-8462-3595

Ashwini A. Patil https://orcid.org/0000-0002-7013-4093

Ravindra V. Adivarekar https://orcid.org/0000-0003-0725-9288

Correspondence-

Name: (Dr.) R.V. Adivarekar,

Address: Head, Department of Fibers \& Textile Processing Technology, Institute of Chemical Technology, (ICT),

Matunga, Mumbai 400 019, Maharashtra, India.

E-mail: - rv.adivarekar@ictmumbai.edu.in

Tel: 022-33612801

\begin{abstract}
Melanin is a ubiquitous pigment found in most organisms, it is a dark-brown or black pigment formed by the oxidation of phenolic compounds. They are negatively charged amorphous compounds having quinone groups. In this study; melanin-producing microorganism was isolated from soil obtained from iron ore mine. The soil was enriched in modified Ashby's glucose broth for 15 days at $30^{\circ} \mathrm{C}$ further to which it was isolated on modified Ashby's agar at $30^{\circ} \mathrm{C}$ for seven days; the colonies showing pigmentation were selected for further study. Conditions were optimized for maximal production of melanin pigment. The effect of carbon, nitrogen, tyrosine, and metal salts on pigment production was studied. Alkaline conditions were used to extract the pigment from cells, further characterized by UV-VIS spectroscopy for $\lambda$-max. FTIR was done to identify the native functional groups, and XRD was performed to determine the melanin's structure. TGA analysis was done to check its thermal stability. SEM was carried out to check the size and shape of the melanin pigment. The melanin pigment was also analyzed for UV protectant property which was studied by exposure of both melanized and non-melanized cells to UV light at $254 \mathrm{~nm}$.
\end{abstract}

\section{Key words:}


Beijerinckia fluminensis, iron ore soil, melanin, and UV-protection.

\section{Introduction}

Melanins are negatively charged, hydrophobic macromolecules of high molecular weight formed by the oxidative polymerization of phenolic or indolic compounds. The resulting pigments are usually brown or black, but other colors have also been observed, depending on the substrate used to induce melanization. Melanin polymers are remarkable in that they have a stable population of organic free radicals. Melanin is widely distributed in living organisms such as bacteria, fungi, plants, animals, and human beings: eumelanins, pheomelanins, allomelanins, and pyomelanins. Eumelanins are formed from quinones and free radicals. Pheomelanins are derived from tyrosine and cysteine. Allomelanins are synthesized from nitrogen-free precursors, and pyomelanins are derived from tyrosine's catabolism via phydroxyphenylpyruvate homogentisic acid (HGA) [1].

Melanin is an enigmatic high-molecular-weight pigment that has been extensively studied and characterized as a negatively charged amorphous compound with quinone groups. Structurally, Melanins are polyanionic molecules that contain a stable population of organic free radicals. Melanin is a dense, rigid, and amorphous complex absorbing material with significant strength. Melanin absorbs electromagnetic waves (or light) throughout the entire ultraviolet (UV) and visible spectrum (VIS) and is therefore photo-protectant and photoconductive [2]. Melanin is an important virulence factor in several human pathogenic fungi due to its anti-oxidative, anti-phagocytic, thermostable, anti-radioactive, paramagnetic, and metal-binding properties. The pigment also offers protection as a cellular scavenger against free radicals, ROS (reactive oxygen species), drugs, oxidants, and xenobiotics [3]. It has been reported that some microorganisms synthesize melanin in response to stress conditions such as high temperature, starvation, or hyperosmotic media. Melanized cells are more resistant to the effects of certain antifungals. Melanin pigment offers resistance to extreme heat and cold to the organism producing it. Various functional groups present on the surface of melanin structure offer heavy metal binding bioabsorption property and can be used for bioremediation [4]. Melanin can store and release endogenous and exogenous compounds, such as zinc, calcium, iron, and protein. Some drugs and other organic and inorganic substances, such as ampicillin, have also shown this pigment's affinity. 
Characteristically, Melanins are insoluble in water or common organic solvents, resistant to concentrated acids, and susceptible to bleaching by oxidizing agents [5].

This study focuses on the isolation of microorganisms from soil contaminated with metals. The aim is to isolate and characterize microorganisms producing melanin and test the UV protectant ability of melanin.

\section{Materials and Methods}

\section{Sample collection, enrichment, isolation, and identification}

The soil samples were collected in a sterile container from the Tumsar region in the Bhandara district of Maharashtra, India. For enrichment; $1 \mathrm{gm}$ of soil sample was inoculated in the $100 \mathrm{ml}$ of Ashby's broth medium and incubated at $30^{\circ} \mathrm{C}$ for 15 days. After enrichment, the isolation was carried out on Ashby's glucose agar and incubated at $30^{\circ} \mathrm{C}$ for 7 days. The culture showing pigmentation was selected and was reisolated on Ashby's glucose agar and preserved for further optimization studies. The culture's identification was based on cultural, morphological, and biochemical characteristics as per Bergey's manual of systematic bacteriology. Nomenclature \& Phylogenetic analysis of bacterial culture has been done using bacterial 16S rRNA gene sequencing ( 1300 bases).

\section{Optimization of growth parameters for maximum pigment production}

\section{Growth medium}

The growth medium was modified with different concentrations of carbon and nitrogen sources, L-tyrosine, and co-factors like Ammonium molybdate tetrahydrate $\left[\left(\mathrm{NH}_{4}\right)_{6} \mathrm{Mo}_{7} \mathrm{O}_{24} .4 \mathrm{H}_{2} \mathrm{O}\right]$, Ferrous sulphate $\left[\mathrm{FeSO}_{4} \cdot 7 \mathrm{H}_{2} \mathrm{O}\right]$, and Magnesium sulphate $\left[\mathrm{MgSO}_{4} .7 \mathrm{H}_{2} \mathrm{O}\right]$ to check the increase in melanin pigment production. To evaluate the optimum carbon source, different concentrations $(0.1,0.2,0.4,0.6,0.8$, and $1.0 \%)$ of glucose, fructose, and sucrose were taken. Different concentrations of Nitrogen (ammonium sulphate) and L-tyrosine were prepared (0.01, 0.02, 0.04, 0.06, 0.08, and 0.10\%). Similarly, different concentrations $(0.01,0.02,0.04,0.06,0.08$, and $0.10 \%)$ of $\left(\mathrm{NH}_{4}\right)_{6} \mathrm{Mo}_{7} \mathrm{O}_{24 .} .4 \mathrm{H}_{2} \mathrm{O}$ and $\mathrm{FeSO}_{4} .7 \mathrm{H}_{2} \mathrm{O}$ were also prepared. 


\section{Effect of aeration, incubation time, pH, temperature, and sunlight}

The isolated culture was challenged with different physical parameters, like aeration, where one set of cultures was kept in an orbital shaker at 120rpm. The other in static condition both were incubated for 30 days at RT. pH selected were $3,4,6,7,8,10,12,13$. The effect of different temperatures $\left(20,24,28,37,40^{\circ} \mathrm{C}\right)$ was also studied on the culture for maximum growth and pigment production. The culture inoculum was adjusted to 0.1O.D, and the media flasks $(100 \mathrm{ml})$ were kept for a week, and the interpretation was made by measuring absorbance at $400 \mathrm{~nm}$ using a UV-Vis spectrophotometer. [6].

\section{Growth characteristics of Beijerinckia fluminensis}

The organism's growth curve and maximum pigment production were studied using Ashby's glucose and modified Ashby's glucose medium. Estimation was done after the third day of incubation for 30 days. The interpretation was made by measuring the cell density (OD) and pigment absorbance at a fixed wavelength of $\lambda$-max of $600 \mathrm{~nm}$ and $400 \mathrm{~nm}$ [6].

\section{Extraction of melanin pigment}

The extraction of the pigment was carried out using standard alkali solutions like $\mathrm{NaOH}$, $\mathrm{KOH}, \mathrm{NH}_{4} \mathrm{OH}, \mathrm{Ca}(\mathrm{OH})_{2}, \mathrm{LiOH}$ at varying concentrations of $0.1,0.5,1,1.5,2 \mathrm{~N}$. The extraction was carried out from a thirty-day old culture plate grown on MAG agar. After extraction. The pigment was precipitated using double strength acid like $\mathrm{HCl}(2 \mathrm{~N})$ under slow magnetic stirring conditions. Further, the residue was transferred to a dialysis tube and kept in distilled water for $6 \mathrm{~h}$ with two distilled water changes. After dialysis, melanin was re-dissolved in alkali and precipitated; this was done to altogether remove the unwanted impurities like proteins and other fatty acids present.

\section{Characterization of melanin extracted from Beijerinckia fluminensis}

Characterization of melanin is a difficult task due to its insoluble nature. Scanned literature has shown significant characterizations like UV-Spectroscopy, FTIR, XRD, TGA, and SEM. UV-visible spectroscopy of bacterial melanin was carried out by dissolving the dry pigment in $5 \mathrm{ml}$ of $0.1 \mathrm{~N} \mathrm{NaOH}$, and absorbance was recorded using UV-1800 Shimadzu 
spectrophotometer against $\mathrm{NaOH}$ as blank. The spectra were compared with the standard melanins (isolated from bacteria and cuttlefish, Sepia Officinalis). FTIR (FTIR-8400S Shimadzu) was performed to confirm native groups of melanin compared with the other natural melanin present in higher organisms. XRD analysis was carried using Lab X, XRD6100 of Shimadzu, after drying the melanin at $200^{\circ} \mathrm{C}$ and converting it into a fine powder. TGA data were recorded in an aluminum pan using 10mg melanin samples using a TGA Shimadzu (DTG-60H, Japan) thermal analyzer under an atmosphere of nitrogen from $30^{\circ} \mathrm{C}$ to $500^{\circ} \mathrm{C}$ at a heating rate of $10^{\circ} \mathrm{C} / \mathrm{min}$. For SEM analysis, melanin was dried, and finely powdered melanin was mounted on an SEM stub (diameter, $12 \mathrm{~mm} \times 12 \mathrm{~mm}$ ) using carbon tabs. It was coated with $\mathrm{Au} / \mathrm{Pd}$ in a sputter coater, and the specimen was then scanned in FEG-Philips XL 30 SEM.

\section{UV resistance property of bacterial melanin}

Photo-protectant property of melanin was checked by initially growing the cells in two flasks a) Modified Ashby's glucose broth (MAG) and b) MAG broth with L-ascorbic acid, which prevents the formation of melanin. These were incubated for 5 days on shaker condition at $25^{\circ} \mathrm{C}$. On the $7^{\text {th }}$ day, $10 \mathrm{ml}$ of culture aliquots, each from both the sets (a and b), were taken in ten sterile empty Petri dishes under aseptic condition and exposed to UV radiation (254 $\mathrm{nm})$ for different time intervals $(0,2,4,6,8,10,15,20,25,30 \mathrm{~min})$ at a distance of $30 \mathrm{~cm}$ from base to UV lamp.

Further, from each plate, $0.1 \mathrm{ml}$ of aliquot is added to $10 \mathrm{ml} \mathrm{MAG} \mathrm{broth} \mathrm{to} \mathrm{check} \mathrm{cell} \mathrm{death} \mathrm{at}$ a particular time of UV exposure. At the same time, loopful was streaked on Modified Ashby's glucose agar plates. Tubes and plates were incubated for $72 \mathrm{~h}$, at $25^{\circ} \mathrm{C}$. The result's interpretation was noted based on turbidity observed in the tubes and the recovery of growth on the line streaked on MAG agar plates. 


\section{Results}

\section{Enrichment, isolation, and characterization}

Isolation and characterization

Isolation from the enriched broth on Ashby's glucose agar showed large slimy colonies with pigmentation. These colonies were selected and reisolated on fresh agar plates. After growing extensively for 7 to 30 days, light brown to black pigmentation with slimy consistency was seen, which was maybe due to the production of polyhydroxbutarate (PHB) (Fig. 1). The growth biochemistry of Beijerinckia shows the utilization of glucose, fructose, and sucrose. The organism is catalase-positive with the presence of urease but absence of nitrate reduction capability. The optimal growth is seen between $20-30^{\circ} \mathrm{C}$ and between $\mathrm{pH} 3.0$ and $\mathrm{pH} 9.0$. When observed under the microscope, the cells appear straight or slightly curved rods with rounded ends. Cells occur singly or appear as dividing pairs. Intracellular granules of poly-bhydroxybutyrate (PHB) are formed, generally one at each pole. Gram-negative, motile by peritrichous flagella or nonmotile $[7,8]$.

The culture's physical and biochemical characteristics partially confirm the isolate to be from the Azotobacter spp. or Beijerinckia spp. (Table 1). Table 2 shows the 16S ribosomal RNA sequence, which confirms the Beijerinckia genus of the isolated strain, and the NCBIBLAST analysis showed $100 \%$ homology with the Beijerinckia fluminensis strain UQM $1685^{\mathrm{T}}[9]$.

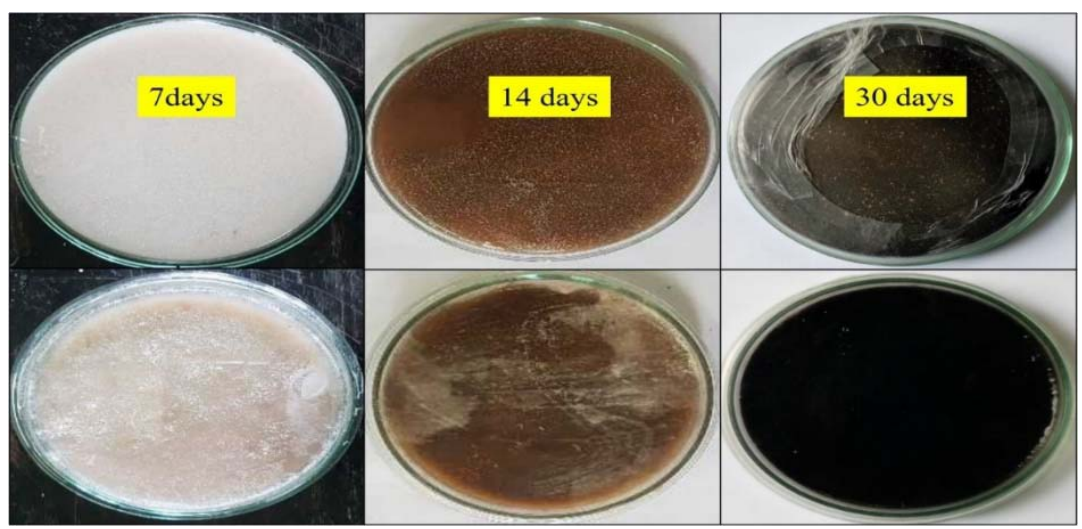


Fig. 1 Ashby's glucose agar plates showing melanin production and growth of isolated bacteria.

Table 1 Physical and biochemical characteristics of a strain isolated from soil.

\begin{tabular}{|l|l|}
\hline Characteristics & Result \\
\hline Colony & Irregular \\
\hline Consistency & Slimy (due to presence of PHB) \\
\hline Pigmentation & Light to dark brown \\
\hline Motility & + \\
\hline Gram nature & gram-negative \\
\hline Nitrate to nitrite reduction & - \\
\hline Urease & - \\
\hline Glucose & + \\
\hline Fructose & + \\
\hline Sucrose & + \\
\hline Mannitol & - \\
\hline Maltose & - \\
\hline Lactose & + \\
\hline Glycerol & + \\
\hline Sorbitol & + \\
\hline Key:,+ positive; - , negative & \\
\hline
\end{tabular}

Table 2 16S ribosomal RNA gene sequence and NCBI-BLAST analysis with Phylogenetic tree of $B$. fluminensis showing homology with the species. 


\begin{tabular}{|c|c|c|c|c|c|}
\hline $\begin{array}{l}\text { Sr. No. } \\
1 .\end{array}$ & $\begin{array}{r}\text { Strain } \\
\text { Seq 34_AZM_ } \\
\text { NC160318A } \\
\\
100 \\
\end{array}$ & $\begin{array}{l}\text { Aim } \\
\text { Identification } \\
\text { of } 16 \mathrm{~S} \text { rRNA } \\
\text { gene }\end{array}$ & 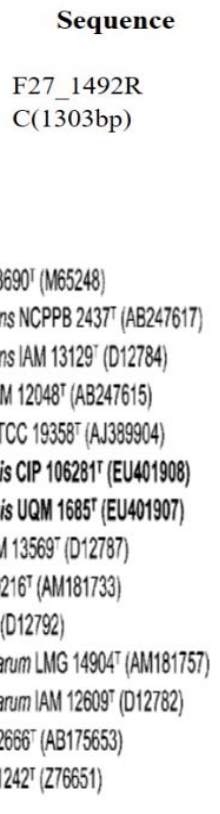 & $\begin{array}{l}\quad \text { NCBI BLAST } \\
\text { • } \quad \text { NR_116306 } \\
\text { Beijerinckia fluminensis } \\
\text { Identities: } \\
\text { 1302/1303(99\%) } \\
\text { Int. J. Syst. Evol. } \\
\text { Microbiol. 59 (PT 9), } \\
\text { 2323-2328 (2009) } \\
++\quad \\
\text { - } \quad \text { NR_115516 } \\
\text { Agrobacterium } \\
\text { tumefaciens } \\
\text { Identities: } \\
\text { 1296/1303(99\%) } \\
\text { J. Gen. Appl. Microbiol. } \\
\text { 49 (3), 155-179 (2003) } \\
\text { ++ } \\
\text { • NR_116874 } \\
\text { Rhizobium pusense } \\
\text { Identities: } \\
\text { 1294/1304(99\%) } \\
\text { Int. J. Syst. Evol. } \\
\text { Microbiol. 61 (PT 11), } \\
\text { 2632-2639 (2011) }\end{array}$ & $\begin{array}{l}\quad \text { Remarks } \\
\text { Strain shows } \\
\text { closer } \\
\text { homology with } \\
\text { Beijerinckia sp. } \\
\text { (Closer } \\
\text { to fluminensis) }\end{array}$ \\
\hline
\end{tabular}

\section{Optimization studies}

\section{Optimization for maximum pigment production}

Optimization of pigment production results showed the strain could utilize all three carbon sources and indicated that as the sugars' concentration increases, the pigment production also increased exponentially. The culture showed a high melanin production rate while growing on glucose as the sole source of carbon (Fig. 2). The effect of L-tyrosine was significant on melanin production since it is one of the main precursors in the melanin pathway. The effect nitrogen source was not substantial, and the pigment production over the range was average (Figure 3). Figure 4 shows the effect of growth co-factors like ammonium molybdate tetrahydrate $\left[\left(\mathrm{NH}_{4}\right)_{6} \mathrm{Mo}_{7} \mathrm{O}_{24} \cdot 4 \mathrm{H}_{2} \mathrm{O}\right]$, ferrous sulphate $\left[\mathrm{FeSO}_{4} \cdot 7 \mathrm{H}_{2} \mathrm{O}\right]$, and Magnesium sulphate $\left[\mathrm{MgSO}_{4} .7 \mathrm{H}_{2} \mathrm{O}\right]$, which showed a positive growth response in maximizing pigment production from $0.04 \%$ to $0.06 \%$ concentration. Beijerinckia sp are aerobic and grow well in conditions having optimum oxygen levels. This study was carried out to analyze the effect of aerobic conditions on melanin production. Melanin production was significant in the culture flask kept in an orbital shaker, which showed melanin production in six days. 
In contrast, the flask kept static showed melanin production after ten days. As the incubation time increased, the melanin production also increased, which was studied for thirty days. Beijerinckia cells grow slowly and require the right amount of oxygen for PHB production. In shaker conditions, the cells utilize growth nutrients faster and move early to the stationary phase, which results in the transition of older cells to stress conditions, leading to melanin production (Fig. 5) [10,11].

The $\mathrm{pH}$ of the medium and incubation temperature plays a vital role in the functioning of the cell's metabolic activities. The earlier studies understand that the Beijerinckia sp. grows better in the $\mathrm{pH}$ range of 3.0 to 9.0 at an optimal temperature of $25^{\circ} \mathrm{C}$ to $30^{\circ} \mathrm{C}[13,14]$. Keeping this information in mind, the effect of different $\mathrm{pH}$ and temperature was studied on melanin production, and it was found that the maximum output of melanin was seen from $\mathrm{pH}$ 4.0 to $\mathrm{pH} 6.0$ and the optimal growth temperature for significant melanin production was $30^{\circ} \mathrm{C}$ (Fig. 6).

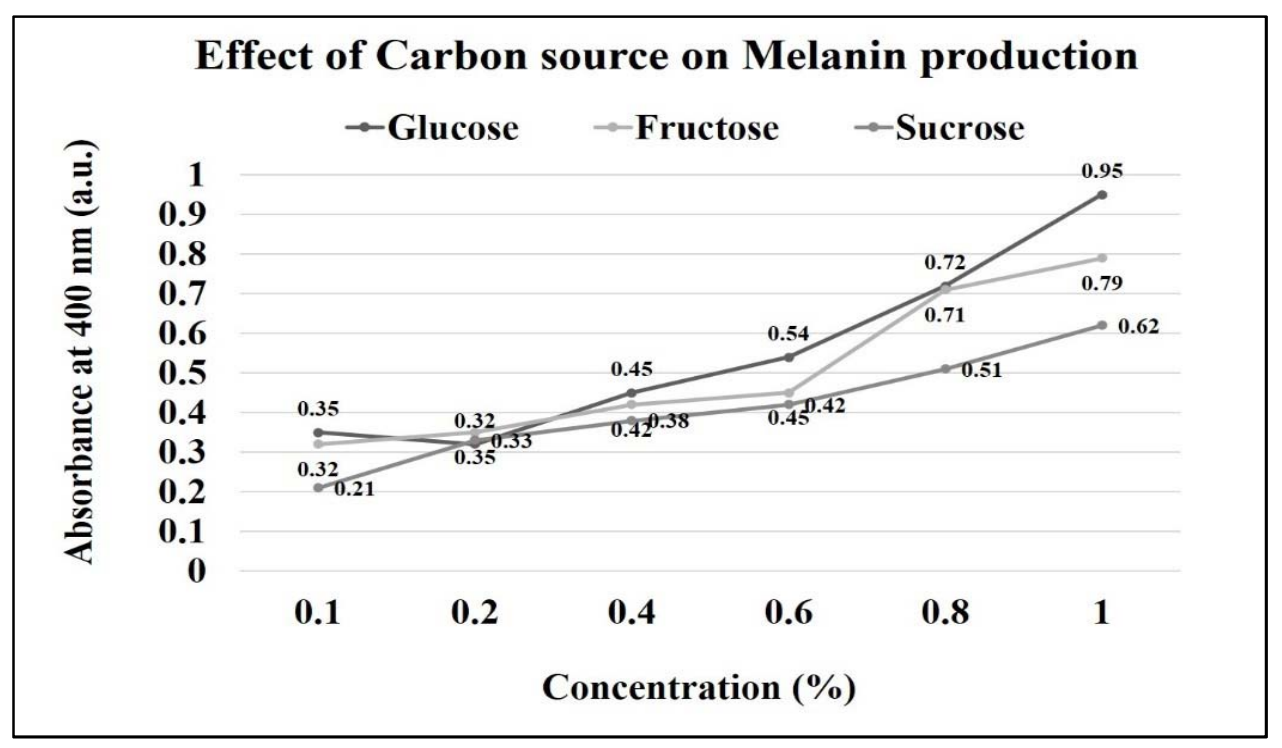

Fig. 2 Effect of carbon source on melanin production 


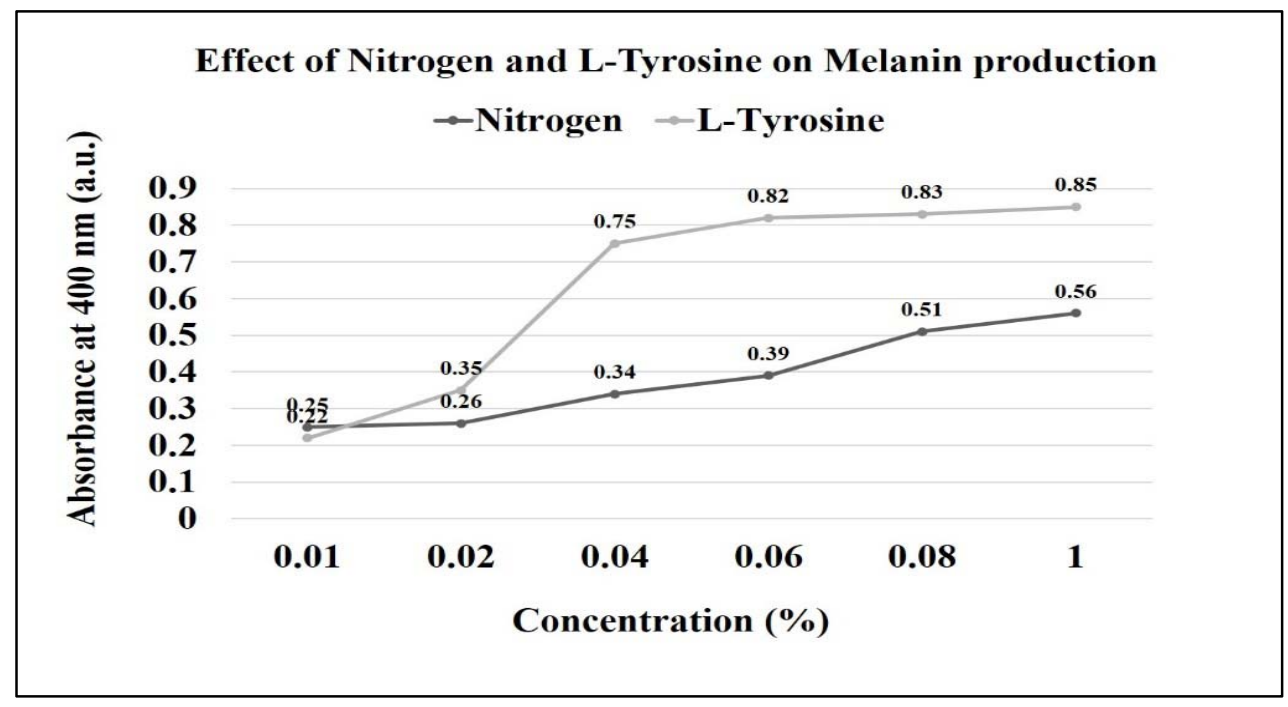

Fig. 3 Effect of nitrogen and L-tyrosine on melanin production

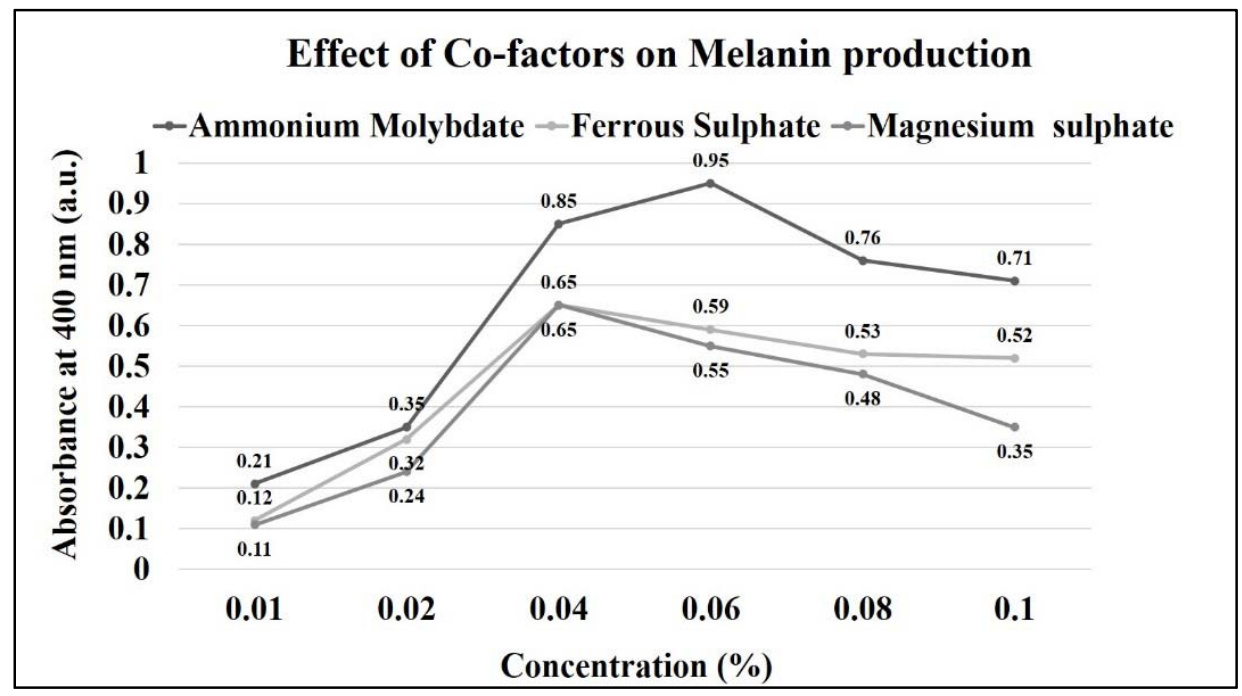

Fig. 4 Effect of co-factors on melanin production 


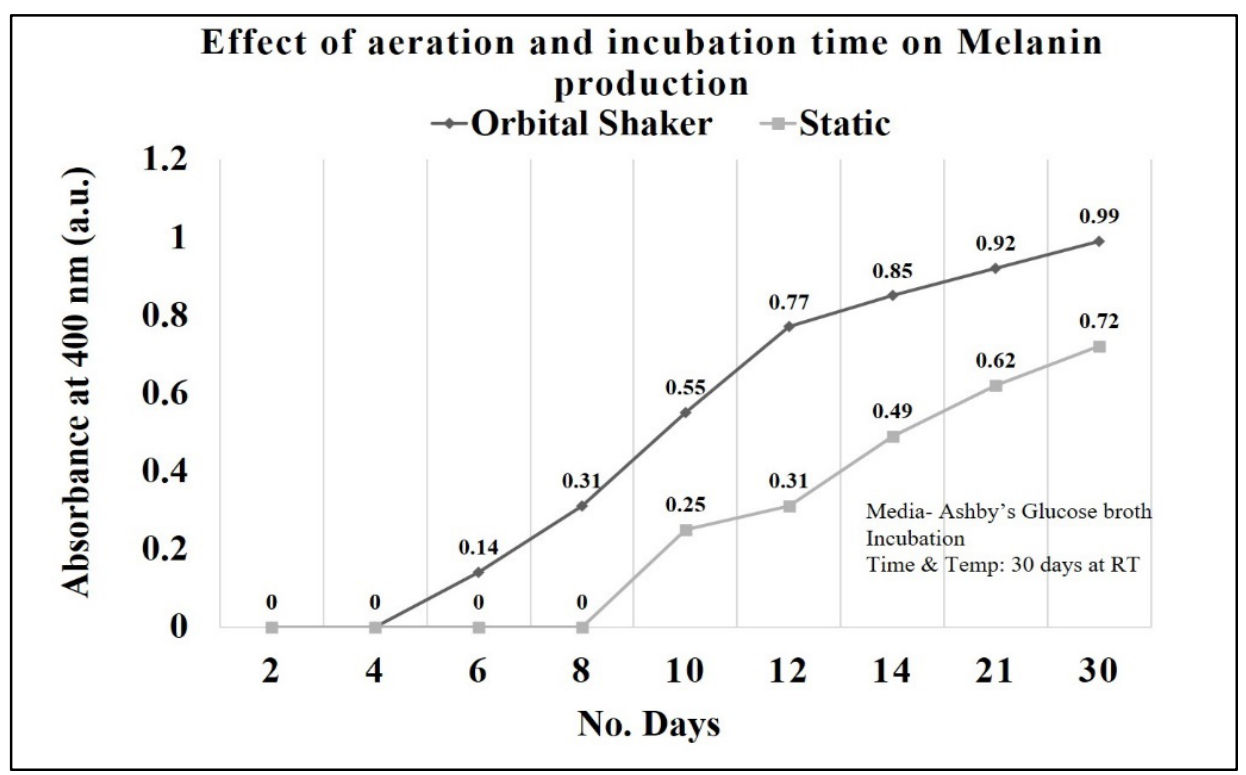

Fig. 5 Effect of aeration and incubation time on melanin production in B. fluminensis

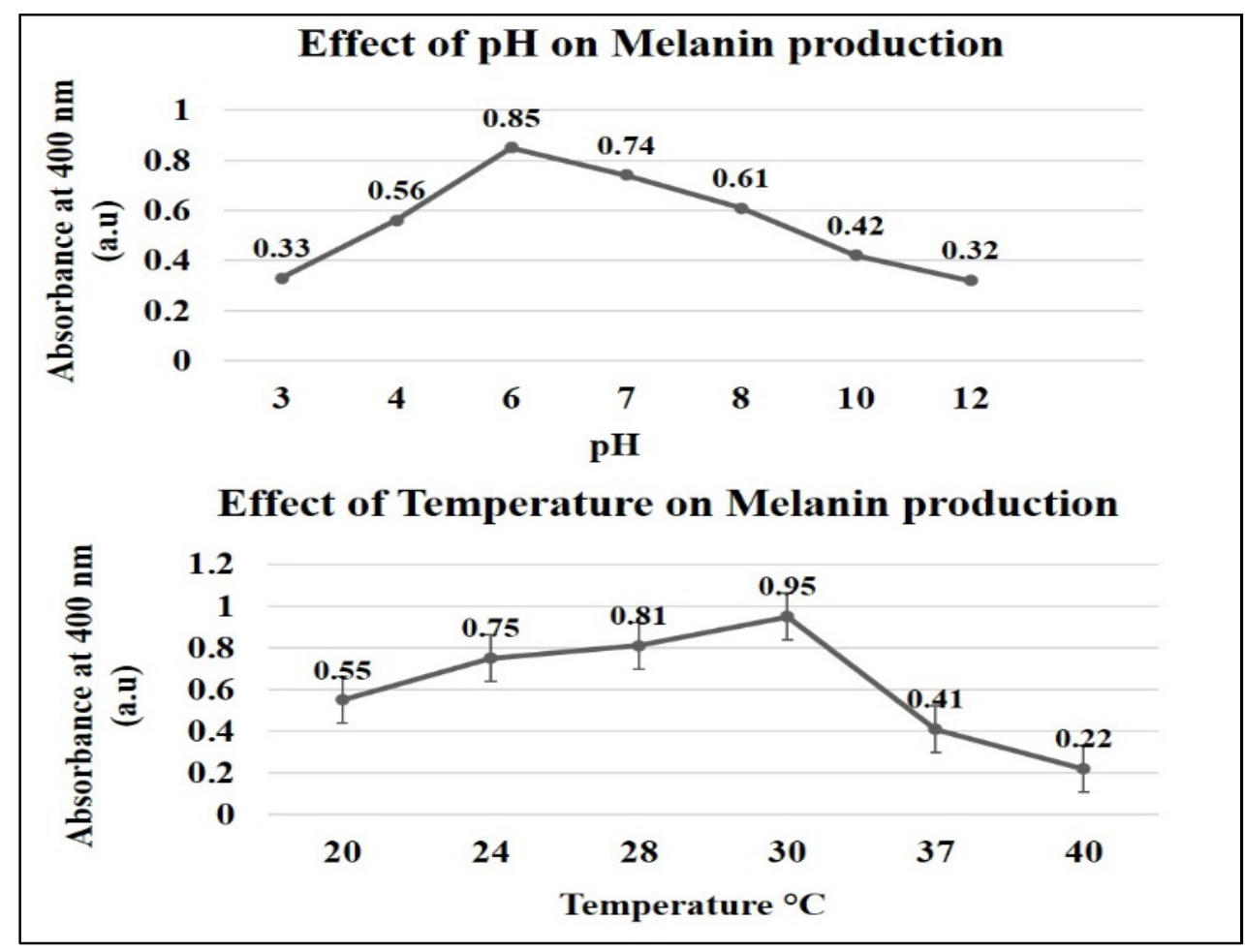

Fig. 6 Effect of $\mathrm{pH}$ and temperature melanin production in $B$. fluminensis

\section{Growth characteristics of Beijerinckia fluminensis}

The growth characteristics and pigment production of B. fluminensis in Modified Ashby's glucose medium were better than those in the non-modified medium. The presence of 
Nitrogen, L-tyrosine, and co-factors in the medium was found to enhance the growth and double the melanin production of the culture (Fig. 7).

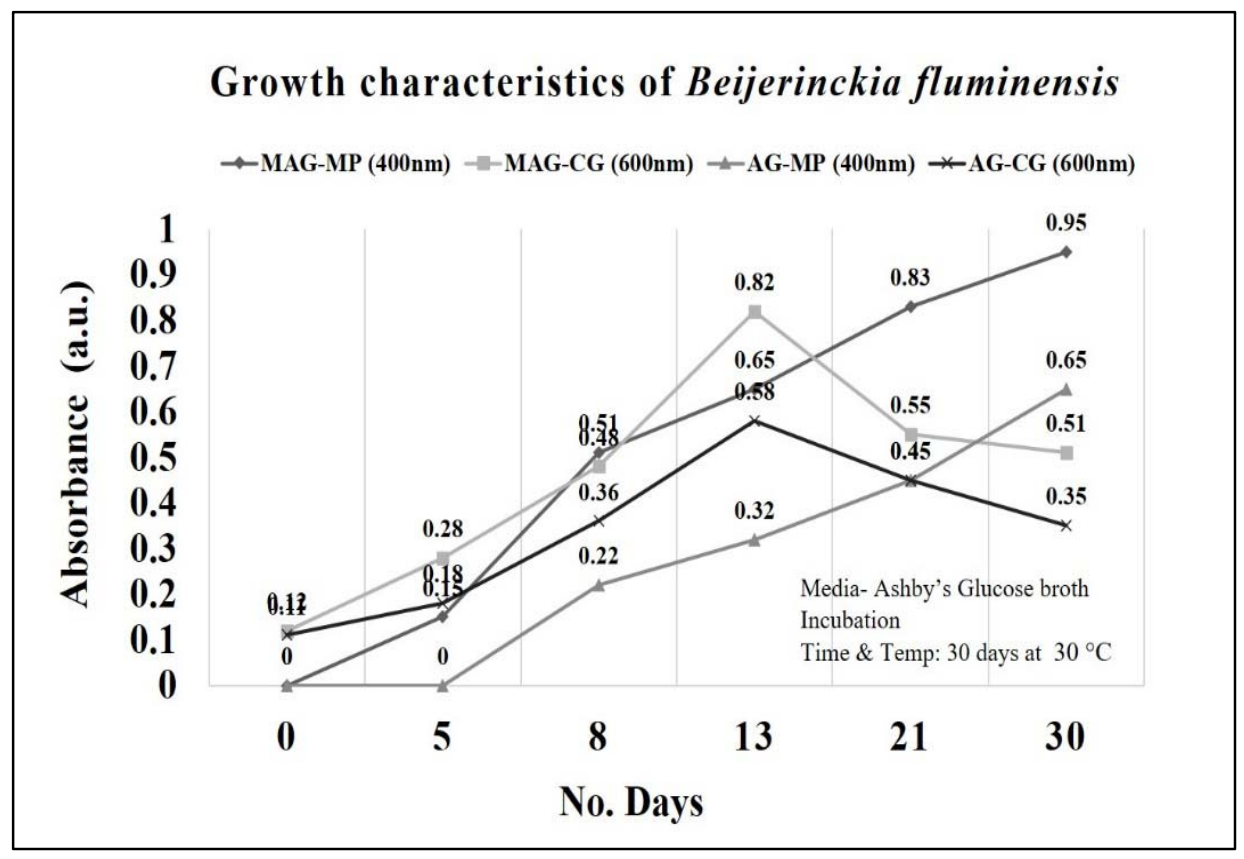

Fig. 7 Growth characteristics of B. fluminensis in Ashby's glucose (AG) and modified Ashby's glucose (MAG)

\section{Extraction of melanin pigment from grown culture}

From the literature, it is evident that the melanins are only soluble in alkaline conditions. The melanin pigment extraction was carried out from the isolate, grown on Ashby's glucose agar for thirty days (Fig 8). 1 $\mathrm{gm}$ of the solid media was transferred in tubes having $10 \mathrm{ml}$ of different alkalis. The tubes were vortexed, and the solutions were kept in a sonication bath for $30 \mathrm{~min}$. Based on the solution's clarity, results were noted as either "soluble" or "insoluble." The melanin showed better extractability in strong alkalis like sodium hydroxide and potassium hydroxide (Table 3). 


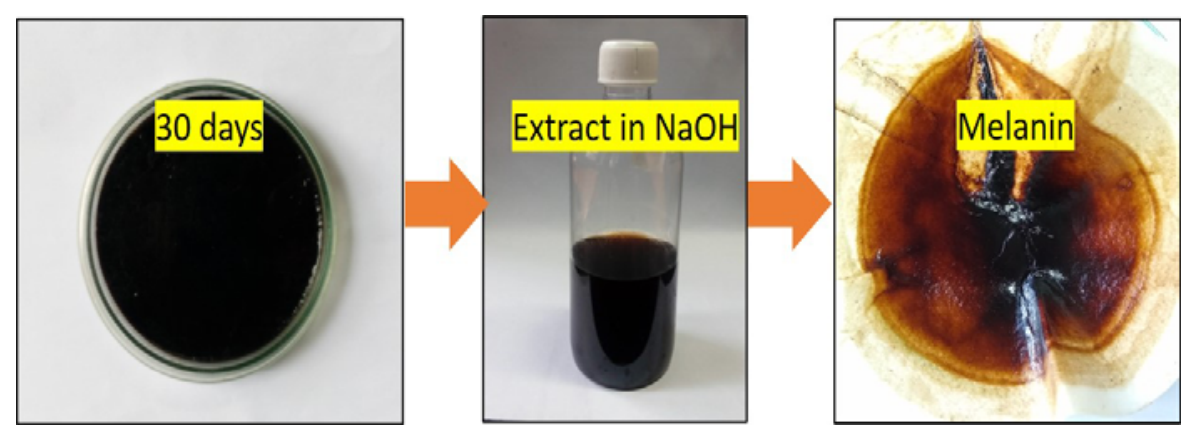

Fig. 8 Extraction of Melanin from the thirty-day old grown culture of B. fluminensis

Table 3 Extraction of melanin from B. fluminensis in different alkalis

\begin{tabular}{|l|l|l|l|l|l|}
\hline \multicolumn{7}{|l|}{ Alkali (10ml) } \\
\hline $\begin{array}{l}\text { Concentration } \\
(\mathbf{N})\end{array}$ & $\mathrm{NaOH}$ & $\mathrm{KOH}$ & $\mathrm{NH}_{4} \mathrm{OH}$ & $\mathrm{Ca}(\mathrm{OH})_{2}$ & $\mathrm{LiOH}$ \\
\hline 0.1 & + & - & - & - & - \\
\hline 0.5 & ++ & - & - & - & - \\
\hline 1 & +++ & + & - & - & - \\
\hline 1.5 & +++ & ++ & + & - & - \\
\hline 2 & +++ & ++ & + & + & + \\
\hline $\begin{array}{l}\text { Key: (-) Insoluble, (++) weakly soluble, }(++) \text { moderately soluble, }(+++) \text { highly } \\
\text { soluble. }\end{array}$
\end{tabular}

\section{Characterization of melanin from Beijerinckia fluminensis}

The melanin pigment isolated from the bacteria was characterized by determining the $\lambda$-max using a 200-800 nm scanning range using a UV-Visible Spectrometer. The scan showed a peak in the UV region at $280 \mathrm{~nm}$ and was seen to decrease gradually. Mostly, the absorption was highest in the UV region at 200-300 nm (Fig. 9), which is known as the characteristic property of melanin $[19,28]$. The FTIR spectra (Fig.10) of melanin show a broad absorption peak at $3433 \mathrm{~cm}^{-1}$ and $3344 \mathrm{~cm}^{-1}$ which was due to the $-\mathrm{OH}$ and $-\mathrm{NH} 2$ groups' stretching vibration. The peak observed at around $2857 \mathrm{~cm}^{-1}$ is assigned to $\mathrm{C}-\mathrm{H}$ stretching vibration. The peak appearing in this range was typical of aromatic $\mathrm{C}-\mathrm{H}$ groups from indole moieties in melanin pigment molecules. The absorption peak at $1676 \mathrm{~cm}^{-1}$ and $1618 \mathrm{~cm}^{-1}$ attributed to 
$\mathrm{C}-\mathrm{C}$ or $\mathrm{C}-\mathrm{O}$ stretching and that at $1460 \mathrm{~cm}^{-1}$ due to $\mathrm{C}-\mathrm{H}$ bending mode were obtained from the spectra of other microbial melanin pigments [24,25].

The XRD spectrum (Fig. 11) of the dry melanin shows a broad diffraction peak $\left(2 \theta=15-25^{\circ}\right)$. Such broad peaks indicate non-Bragg features and present different orientations of the structural elements, which are random. Broad peaks are also characteristics of amorphous nature, which is seen in melanins. Melanin structures are uncertain [26,28] due to the amorphous, heterogeneous and insoluble nature of these pigments. TGA analysis of melanin show stability of the pigment at the higher temperatures of $500^{\circ} \mathrm{C}$. Between $300^{\circ} \mathrm{C}$ and $400^{\circ} \mathrm{C}$, the weight loss was $50 \%$, a high percentage of which could be explained by considering melanin degradation because the purification processes removed all cellular molecules (Figure 12). A gradual weight loss was observed up to $500^{\circ} \mathrm{C}$, indicating the complete combustion of melanin pigment. The SEM micrographs show irregular sizes of melanin particles $(20 \mu \mathrm{m}$ to $2 \mu \mathrm{m})$, which may be due to the melanin particles' aggregation after drying (Fig 13). Melanins from different sources show different microstructures [29-32].

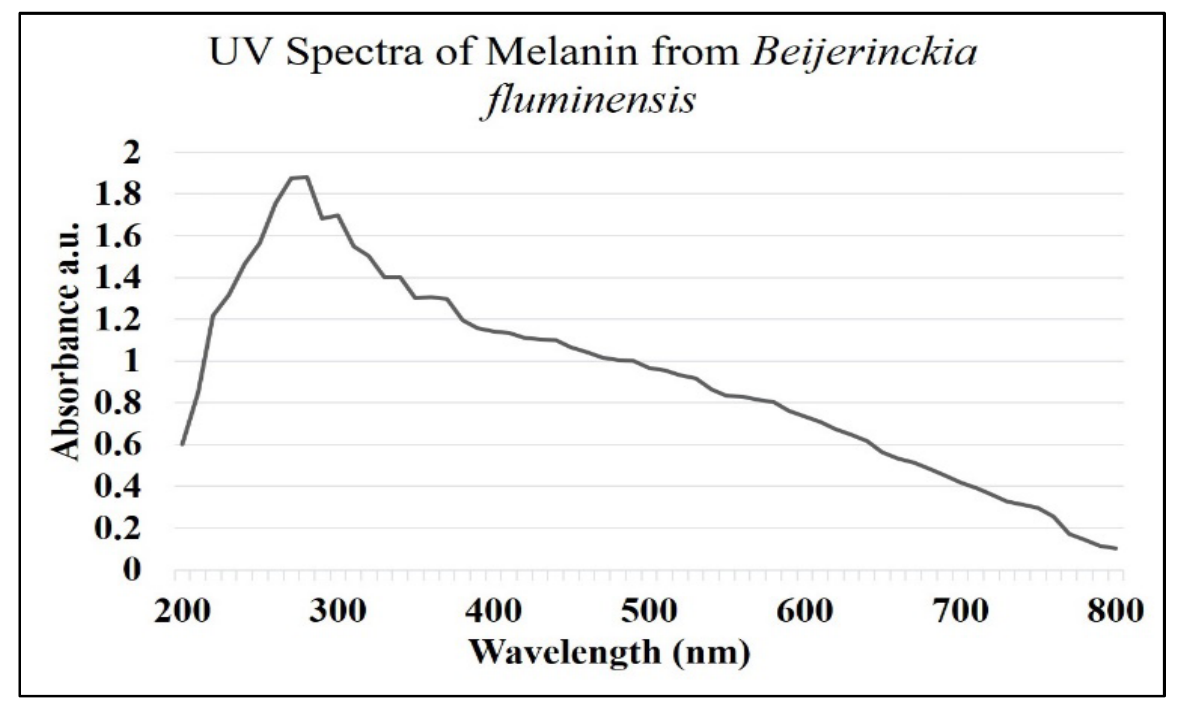

Fig. 9 The UV-VIS Spectra of melanin from B. fluminensis 


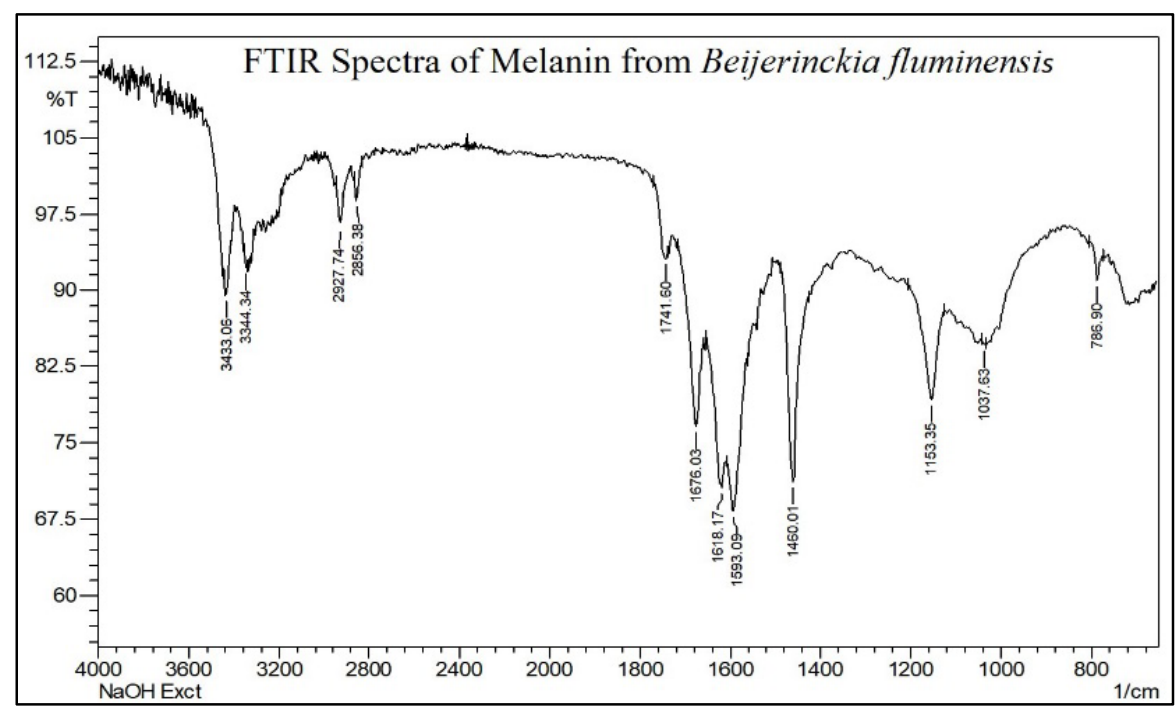

Fig. 10 The FTIR spectra of melanin from B. fluminensis

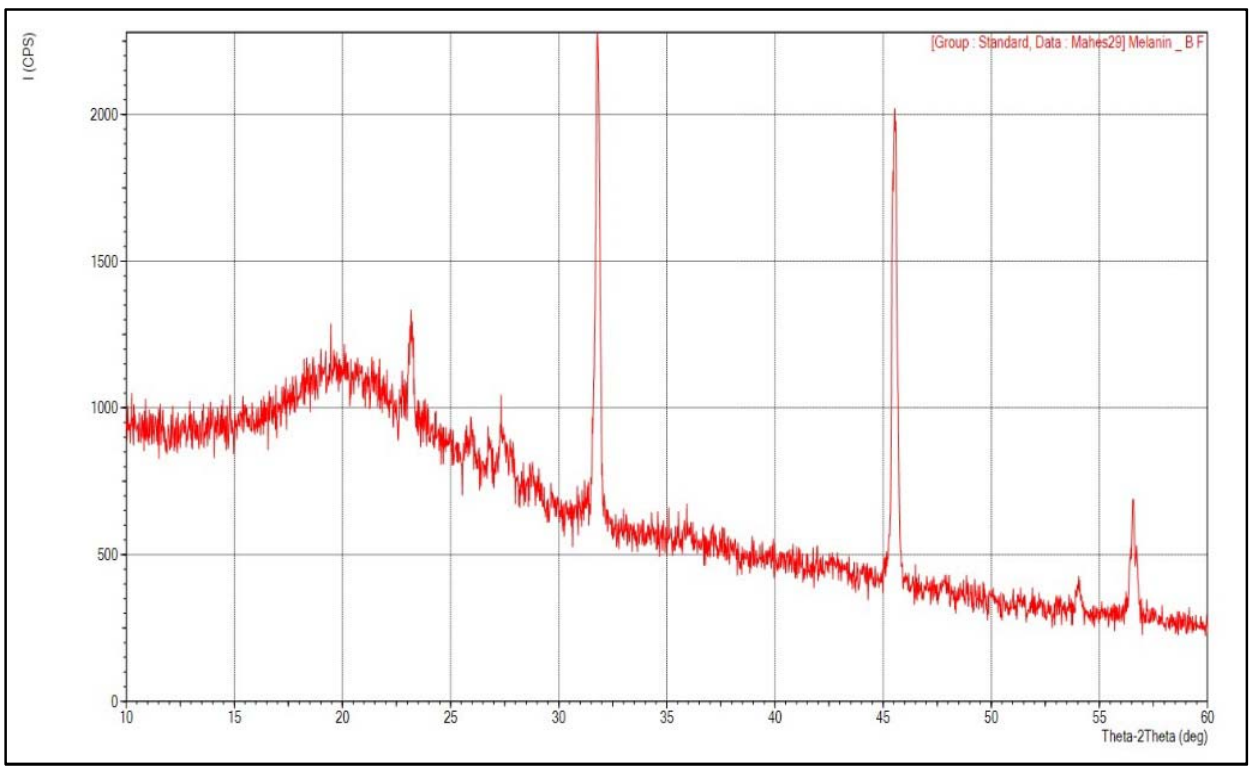

Fig. 11 The XRD analysis of melanin from B. fluminensis 


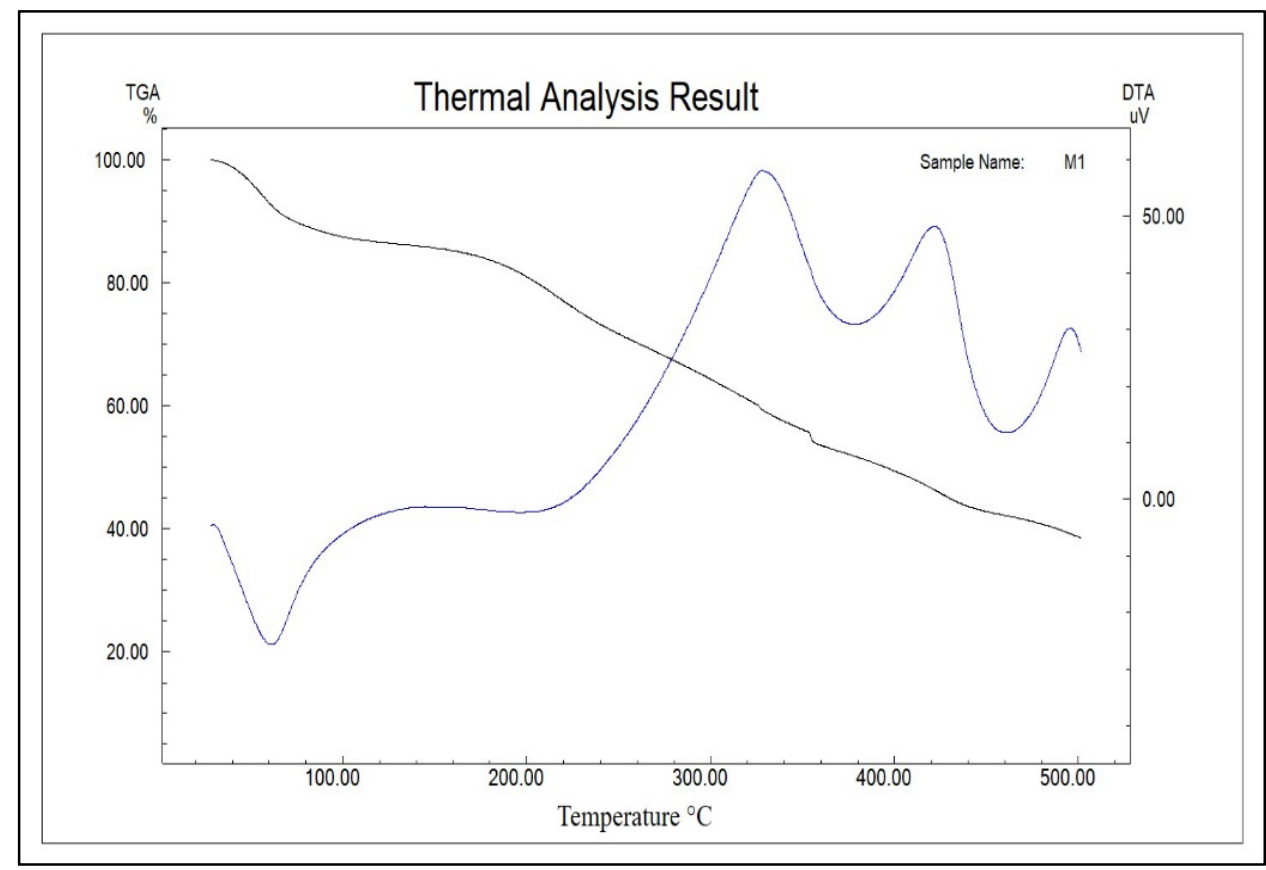

Fig. 12 TGA thermogram of melanin from B. fluminensis

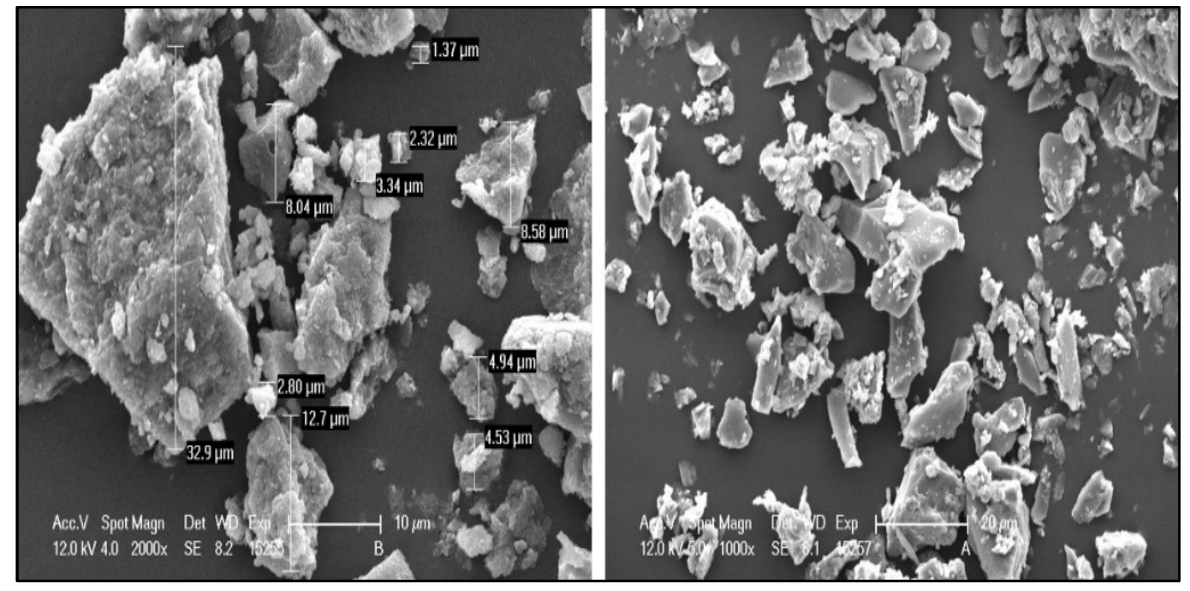

Fig. 13 SEM analysis of melanin from B. fluminensis showing irregular sizes

\section{UV resistance property of melanin from Beijerinckia fluminensis}

The UV-resistant property of bacterial melanin was tested using Beijerinckia fluminensis as the study model (Fig.14). The bacterial cell's ability to produce melanin is suppressed using L-Ascorbic acid in modified Ashby's broth. Both suppressed cells and normal cells were then exposed to UV radiation $(254 \mathrm{~nm})$ and showed variable results which are presented in table 4. The normal cells producing melanin showed no growth in 20 min of UV exposure, which 
was confirmed by the broth's absence of growth and on plates incubated for more than seven days. The suppressed cells showed senescence in $8 \mathrm{~min}$ of UV exposure time, where no growth was observed in further incubation.

Table 4 Evaluation of UV Protection property of melanin produced by B. fluminensis

\begin{tabular}{|l|l|l|l|l|}
\hline Exposure Time (min) & $\begin{array}{l}\text { Modified Ashby's glucose } \\
\text { broth }\end{array}$ & \multicolumn{2}{l}{$\begin{array}{l}\text { Modified Ashby's glucose broth } \\
\text { \& L-ascorbic acid }\end{array}$} \\
\hline & Broth & Plate & Broth & Plate \\
\hline Media Control & - & - & - & - \\
\hline 0 & + & + & + & + \\
\hline 2 & + & + & + & + \\
\hline 4 & + & + & + & + \\
\hline 6 & + & + & + & + \\
\hline 8 & + & + & - & - \\
\hline 10 & + & + & - & - \\
\hline 15 & + & + & - & - \\
\hline 20 & - & - & - & - \\
\hline 25 & - & - & - & - \\
\hline 30 & - & - & - & \\
\hline Key: $(+)$ Growth $(-)$ No growth & - & & & - \\
\hline
\end{tabular}

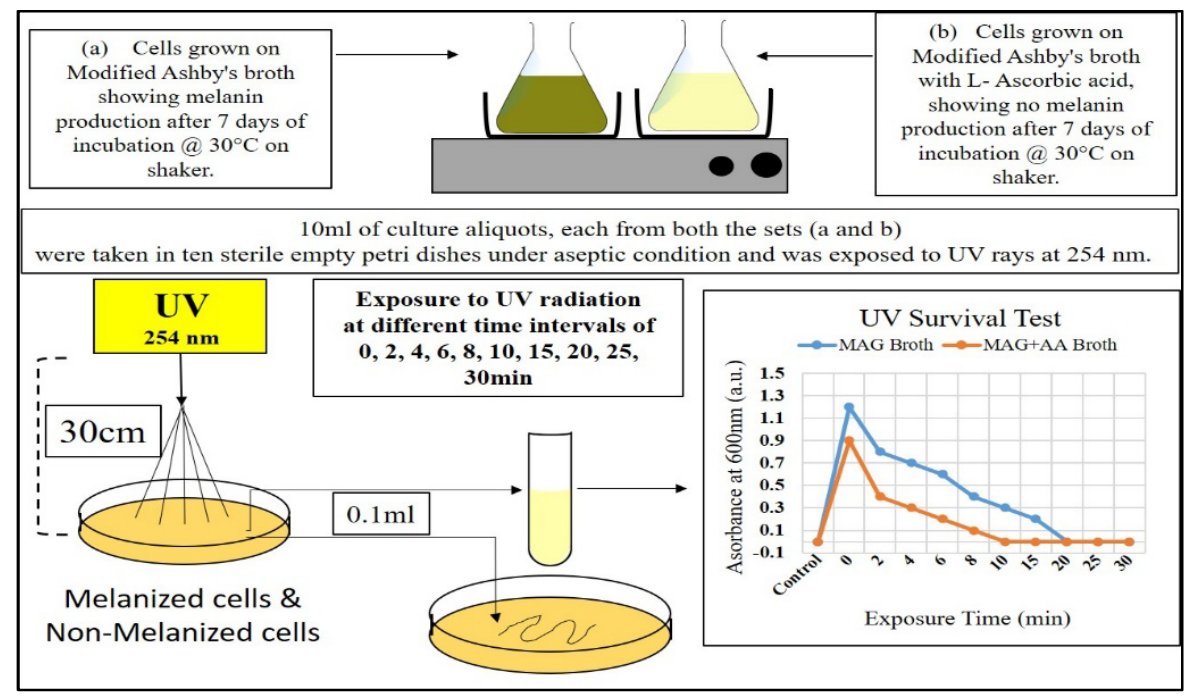

Fig. 14 Schematic representation of UV the survival test of $B$. fluminensis cells exposed to $\mathrm{UV}$ radiation at $254 \mathrm{~nm}$.

\section{Discussion}


The present study provides data for melanin pigment production from a non-pathogenic simple soil bacterium. Lasker et al. 2010, found Beijerinckia sp. in soil samples while studying rice plants' rhizosphere [7]. It was observed that the optimum conditions like temperature and $\mathrm{pH}$ required for maximal pigment production from $B$. fluminensis were found significant. Oggerin et al. 2009, had studied the 16S rRNA gene sequence of $B$. fluminensis strains UQM $1685^{\mathrm{T}}$ and CIP $106281^{\mathrm{T}}$ and found that it was $90-91 \%$ similar to the other Beijerinckia species and subspecies [9]. Barbosa et al. [10] observed an increase in slime production and cell density in $B$. derxii over the time when glucose was the sole carbon source. Barbosa et al. 2002, have also shown that co-factors like metal salts and aerobic conditions are essential for the cell growth and specific nitrogenase activity of $B$. derxii strain ICB-10 [11]. Becking, observed that Beijerinckia species grow in the $\mathrm{pH}$ range of 3.0 to 9.0 at an optimal temperature of $25^{\circ} \mathrm{C}$ to $30^{\circ} \mathrm{C}[12,13,14]$. They also require iron and molybdenum for optimal growth and $\mathrm{N}_{2}$ fixation; the molybdenum requirement was in the range 4.0-35.0 mg/l. The extraction of melanin from sources like hairs, cuttlefish, or microorganisms is extracted using either acid or bases. Generally, it is seen that melanins have good solubility in mild to strong bases like sodium and potassium hydroxide [15,29]. Bacterial melanin extraction is generally challenging due to cell membrane resistance; hence pretreatment with acids like HCL is necessary [15]. Extraction of fungal melanin from Boltus griseus was carried out using $1 \mathrm{M} \mathrm{NaOH}$ with the treatment of $6 \mathrm{M}$ HCL [16,17]. Similar extractions were observed for microorganisms like $C$. neoformans and $C$. sphaerospermum [18].

Melanin has unique UV absorption spectra; first, sharp peaks are seen between 200-300nm, and the further the curve moves downwards monotonically. Aghajanyan et al. 2011, have seen a similar UV absorption trend in bacterial melanin [19]. These absorption characteristics were consistent with the UV-visible absorption spectra of the melanins from sources like fungi, bacteria, and melanin from sepia officinalis [20,21,22]. The FTIR spectra of melanins show bands that appear in the aromatic region having $-\mathrm{C}-\mathrm{H}$ groups, carbonyl $-\mathrm{C}=\mathrm{O}$, a carboxylic acid group $-\mathrm{COOH}$ and $-\mathrm{NH}$ groups which are the main functional groups seen in melanins. Selvakumar et al. 2008, Araujo et al. 2012, and Joshi et al. 2019, had observed similar FTIR absorption peaks while studying melanins from a Pleurotus cystidiosus, marine sponges, and human hairs. The XRD spectra show a broad peak which is characteristic of 
melanin showing amorphous nature due to the non-Bragg features [26,28]. Thermogravimetric analysis of bacterial melanin showed higher temperature stability and is similar to that of a previously reported melanin [27,28]. Bacterial melanin isolated from Streptomyces glaucenscens shows porous and irregular structure [29,30]. Melanin from Proteus mirabilis is rounded aggregates of spherical bodies [31]. Similarly, Pseudomonas sp. and Escherichia coli produced melanin is found to be amorphous deposits with no differentiable structures and small granules [32].

L-ascorbic acid has a reducing effect on melanins' precursors, e.g., it reduces the odopaquinone back to dopa, thus avoiding dopachrome and melanin formation [33,34]. Melanin-producing cells have a higher survival rate compared to non-melanized cells against UV radiation. The primary effect of UV rays is that it attacks the cell's DNA as it contains high-energy photons. It leads to the formation of various mutations in (i.e., pyrimidine dimers, cross-linking of DNA and protein) the cell and undergoes senescence in the early growth phase. Other than the effect on DNA, the UV rays also have a role in producing reactive oxygen-derived free radicals, which directly impact the cell's metabolic function. Thus, melanin plays a vital role in absorbing UV radiation and possibly prevents cellular damage $[35,36]$.

\section{Conclusion}

The present study provides data for melanin pigment production from a non-pathogenic soil bacterium. The biochemical and genetic analysis of the isolate confirmed the genus and species of the bacterium to Beijerinckia fluminensis. Optimum conditions required for maximal pigment production from Beijerinckia fluminensis was found significant. The physical parameters and shake flask data can be useful to carry out scale up for bulk production. Photo-protectant property of the melanin pigment were studied and thus confirms that melanin protects Beijerinckia fluminensis from harmful environmental conditions.

\section{Conflict of Interest}

The authors declare that there is no conflict of interests. 


\section{REFERENCES}

[1] Hamilton, A. J, Gomez, B. L. (2002) Melanins in fungal pathogens. J Med Microbiol, 51, 18991.

[2] Abbas, M., D’Amico, F., Morresi, L., Pinto, N., Ficcadenti, M., Natali, R., Ottaviano, L., Passacantando, M., Cuccioloni, M., Angeletti, M., Gunnella, R. (2009). Structural, electrical, electronic and optical properties of melanin films. Eur Phys JE Soft Matter, 28,285-91.

[3] Jacobson, E. (2000). Pathogenic roles for fungal melanins. Clinic Microbiol. Rev., 13(4),708-17.

[4] Hong, L., Simon, J. (2007). Current understanding of the binding sites, capacity, affinity, and biological significance of metals in melanin. J. Phys. Chem. B., 28, 7938-7947.

[5] Aubry, A. F. (2002). Applications of affinity chromatography to the study of drugmelanin binding interactions. J. Chromatogr B., 768,67-74.

[6] Shivprasad, S., Rage, W. (1989). Catechol formation and melanization by Na+-dependent azotobacter chroococcum: a protective mechanism for aeroadaptation? Appl and Environ Microbiol. 55 (7), 1811-1817.

[7] Laskar, F., Sharma, G. D., Deb, B. (2010). Biodiversity of diazotrophs derxia and beijerinckia in the rhizospheric and nonrhizospheric soils of the rice plant- a review. Bio and Env Sci. 1,154-162.

[8] Kennedy, C. (1950a). Genus I. Beijerinckia Derx, $145^{\mathrm{AL}}$, Bergey's manual of systematic bacteriology., 2,1388.

[9] Oggerin, M., Arahal, D. R., Rubio, V., Marin, I. (2009). Identification of Beijerinckia fluminensis strains CIP 106281T and UQM 1685 T as Rhizobium radiobacter strains, and proposal of Beijerinckia doebereinerae sp. nov. to accommodate Beijerinckia fluminensis LMG 2819. Int. J. of Sys. and Evol. Microbiol., 59, 2323-2328.

[10] Barbosa, H. R., Struckel, Y. F. (1985). Slime production by Beijerinckia derxii - effects of cultural conditions. Soil Biol Biochem., 17,731-732.

[11] Barbosa, H. R., Moretti, M. A., Thuler, D. S., Augusto, E. F. P. (2002). Nitrogenase activity of Beijerinckia derxii is preserved under adverse conditions for its growth. Brazil J. of Microbiol., 33,223-229.

[12] Becking, J. H. (1974). Nitrogen-fixing bacteria of the genus Beijerinckia. Soil Sci., 118,196-212.

[13] Becking, J. H. (1961a). Studies on nitrogen-fixing bacteria of the genus Beijerinckia I. Geographical and ecological distribution in soils. Plant Soil., 14,49-81. 
[14] Becking, J. H. (1961b). Studies on nitrogen-fixing bacteria of the genus Beijerinckia II. Mineral nutrition and resistance to high levels of certain elements in relation to soil type. Plant Soil., 14,297-322.

[15] Singh, D., Kumar, J., Kumar, A. (2018). Isolation of pyomelanin from bacteria and evidences showing its synthesis by 4-hydroxyphenylpyruvate dioxygenase enzyme encoded by hppD gene. Int. J. Biol. Macromol., 119,864-873.

[16] Liu, Q., Xiao, Liu, B., Zhuang, Y., Sun, L. (2018). Study on the preparation and chemical structure characterization of melanin from Boletus griseus. Int. J. Mol. Sci., 19,3736 .

[17] Hou, R., Liu, X., Xiang, K., Chen, L., Wu, X., Lin, W., Zheng, M., Fu, J., Lia, W. (2019). Characterization of the physicochemical properties and extraction optimization of natural melanin from Inonotus hispidus mushroom. Food Chem., 277,533-542.

[18] Dadachova, E., Bryan, R. A., Huang, X., Moadel, T., Schweitzer, A. D., Aisen, P., Nosanchuk, J. D., Casadevall, A. (2007). Ionizing radiation changes the electronic properties of melanin and enhances the growth of melanized fungi. PLoS ONE, 2, e457.

[19] Aghajanyan, A. A., Asaturian, R. A., Hambardzumyan, A. A., Sargsyan, L. B., Hovsepyan, A. S., Vardanyan, A. H., and Saghyan, A. S. (2011). Obtaining of watersoluble microbial melanin and study of its some properties. Appl. Biochem. Microbiol., 47,500-506.

[20] Sajjan, S., Kulkarni, G., Yaligara, V., Kyoung, L., Karegoudar, T. B. (2010). Purification and physiochemical characterization of melanin pigment from Klebsiella sp. GSK. J. Microbiol Biotechnol., 20,1513-1520.

[21] Selvakumar, P., Ralasekar, S., Perisamy, K., Raaman, N. (2008). Isolation and characterization of melanin pigment from Pleurotus cystidosus (telomorph of Antromycopsis macrocarpa). World J. Microbiol. Biotechnol., 24,2125-2131.

[22] Yuan, W., Burleigh, S. H., Dawson, J. O. (2007). Melanin biosynthesis by Frankia strain CeI5. Physiol Plant., 131,180-190.

[23] Araujo, M., Xavier, J. R., Nunes, C. D., Vaz, P. D. (2012). Humanes M. Marine sponge melanin: a new source of an old biopolymer. Struct Chem., 23,115-22.

[24] Kumar, C. G., Sahu, N., Reddy, G. N., Prasad, R. B. N., Nagesh, N., Kamal, V. (2013). Production of melanin pigment from Pseudomonas stutzeri isolated from red seaweed Hypnea musciformis. Lett. Appl. Microbiol., 57,295-302.

[25] Aghajanyan, A. E., Hambardzumyan, A. A., Hovsepyan, A. S., Asaturian, R. A., Vardanyan, A. A., and Saghiyan, A. A. (2005). Isolation, purification and 
physicochemical characterization of water-soluble Bacillus thuringiensis melanin. Pig. Cell Res., 18,130-5.

[26] Lyakh, S. P. (1981). Mikrobnyi melaninogenez I ego funktsii (Microbial melaninogenesis: Its function). Moscow: Nauka., 1(1),224.

[27] Dezidério, S. N., Brunello, C. A., Da'Silva, M. I. N., Cotta, M. A., Graeff, C. F. O. (2004). Thin films of synthetic melanin. J. Non-Crystal Sol., 338-340,634-638.

[28] Joshi, M. H., Patil, A. A., Adivarekar, R. V. (2019). Melanin extraction from human hair by ultrasound assisted alkaline hydrolysis, IJASET,7(1) 2,9-16.

[29] Li, C., Ji, C., Tang, B. (2018). Purification, characterisation and biological activity of melanin from Streptomyces sp. FEMS Microbiol. Lett., 365,1-8.

[30] El-Naggar, N. E. A., El-Ewasy, S. M. (2017). Bioproduction, characterization, anticancer and antioxidant activities of extracellular melanin pigment produced by newly isolated microbial cell factories Streptomyces glaucescens NEAE-H. Sci. Rep., 7,42129 .

[31] Agodi, A., Stefani, S., Corsaro, C., Campanile, F. R. M., Gribaldo, S., Sichel, G. (1996). Study of melanic pigment of Proteus mirabilis. Res. Microbiol., 147,167-74.

[32] Tarangini, K., Mishra, S. (2013). Production, Characterization and analysis of melanin from isolated marine Pseudomonas sp. using vegetable waste. Res. J. Eng. Sci., 2,40-46.

[33] Chang, T. (2009). An updated review of tyrosinase inhibitors. Int J of Mol Sci., 10,2440 -2475 .

[34] Ando, H., Matsui, M., Ichihashi, M. (2010). Quasi-drugs developed in japan for the prevention or treatment of hyperpigmentary disorders. Int J of Mol Sci., 11,2566-75.

[35] Amin, S., Rastogi, R. P., Sonani, R. R., Ray, A., Sharma, A., Madamwar, D. (2018). Bioproduction and characterization of extracellular melanin-like pigment from industrially polluted metagenomic library equipped Escherichia coli. Sci. Total Environ., 635,323-332.

[36] Wang, Y., Casadevall, A. (1994a). Decreased susceptibility of melanized cryptococcus neoformans to UV light. Appl and Environ Microbio., 10,3864-3866. 